\title{
Continuous arteriovenous haemofiltration in children with postoperative cardiac failure
}

\author{
GERFRIED ZOBEL, ALBRECHT BEITZKE, JÖRG I STEIN, MARIJA TROP \\ From the Department of Cardiology, Children's Hospital, University of Graz, Austria
}

SUMMARY Six children with refractory heart failure were treated by continuous arteriovenous haemofiltration. The cause of the failure was postoperative fluid overload or low cardiac output with anuria or oliguria. This produced a mean (2SD) negative fluid balance of $1.4(0.6) \mathrm{ml} / \mathrm{kg} / \mathrm{h}$ and reduced mean (2SD) body weight from $4 \cdot 7(2 \cdot 2)$ to $4.2(2 \cdot 3) \mathrm{kg}$ over a period of $57.5(31 \cdot 1)$ hours. Central venous pressure fell significantly from $13.7(3 \cdot 1)$ to $7 \cdot 7(0 \cdot 7) \mathrm{mm} \mathrm{Hg}$ while the mean (2 SD) arterial pressure increased significantly from $44.6(5.5)$ to $52.6(5 \cdot 1) \mathrm{mm} \mathrm{Hg}$. In three infants urine production resumed when normal blood volume had been achieved. The other three infants needed further haemofiltration because of prolonged renal failure. All but one was weaned from artificial ventilation and catecholamine treatment. No adverse haemodynamic effects were noted. One child need operation for a femoral artery thrombosis after 12 days of continuous arteriovenous haemofiltration.

After paediatric cardiac surgery the main problems are cardiovascular and respiratory. Myocardial damage, ventriculotomy, and a large fluid load (all caused by cardiopulmonary bypass) may result in a low cardiac output state with increased blood volume and pulmonary oedema. ${ }^{1}$ Reduced cardiac output decreases the renal blood supply and leads to sodium and water reabsorption which further increases peripheral and pulmonary oedema. ${ }^{2}$ Inotropes, diuretics, and vasodilators are usually used to stabilise the cardiovascular state. Sometimes, however, the kidneys become resistant to diuretics and gross oedema develops with a consequent further decline in cardiovascular function. In this situation fluid overload can only be corrected by removing fluid from the body. We report our experiences of using continuous arteriovenous haemofiltration in children with congenital heart disease and postoperative fluid overload.

\section{Patients and methods}

From February 1986 to March 1987 six children with congenital heart disease were treated by con-

Requests for reprints to Dr Gerfried Zobel, UniversitätsKinderklinik Graz, Auenbruggerplatz, A-8036 Graz, Austria.

Accepted for publication 22 June 1987 tinuous arteriovenous haemofiltration in the paediatric intensive care unit at the Children's Hospital, University of Graz. Their mean age was 3.6 months (range 7 days to 18 months) and their body weight $4.1 \mathrm{~kg}$ (range 1.7 to $9.5 \mathrm{~kg}$ ). Table 1 shows the patients' clinical data and the indications for continuous arteriovenous haemofiltration. At the start of continuous arteriovenous haemofiltration all children had been oliguric or anuric for up to 12 hours despite diuretic treatment and positive inotropic support. All needed artificial ventilation because of respiratory failure. Their mean ( $2 S D)$ weight gain at the start of continuous arteriovenous haemofiltration was $16.5(12 \cdot 8) \%$. Continuous arteriovenous haemofiltration was carried out as originally described by Kramer et $a^{3}$ or with suction support. The technique has been described elsewhere. ${ }^{45}$ The radial, brachial, and femoral arteries were cannulated to remove blood for haemofiltration and the femoral and internal jugular veins were used to return blood from the extracorporal circuit. The premature infant was treated with a $0.015 \mathrm{~m}^{2}$ polysulphone haemofilter (Amicon Minifilter, Amicon Corporation, Lexington, MA, USA) and the others were treated with a $0.1 \mathrm{~m}^{2}$ polyamide haemofilter (Ultrafilter U-2000 Gambro, Gambro Corporation, Hechingen, West Germany.) The extracorporal filling volumes were 9 and $17 \mathrm{ml}$ respectively. Heparin $(5-10 \mathrm{IU} / \mathrm{kg} / \mathrm{h})$ was given for 
Table 1 Clinical data on children with postoperative congestive cardiac failure

\begin{tabular}{|c|c|c|c|c|c|c|c|}
\hline $\begin{array}{l}\text { Patient } \\
\text { No }\end{array}$ & Age & Sex & $\begin{array}{l}\text { Body weight } \\
\text { (kg) }\end{array}$ & Basic disease & Operation & Complications & Indications for $C A V H$ \\
\hline 1 & 10 days & $\mathbf{F}$ & $3 \cdot 4$ & PA, IVS & $\begin{array}{l}\text { Left sided modified } \\
\text { BTS }\end{array}$ & Hypoxia, sepsis & Hypervolaemia, oliguria \\
\hline $\begin{array}{l}2 \\
3\end{array}$ & $\begin{array}{l}10 \text { days } \\
6 \text { weeks }\end{array}$ & $\begin{array}{l}\mathbf{M} \\
\mathbf{M}\end{array}$ & $\begin{array}{l}3 \cdot 2 \\
3 \cdot 5\end{array}$ & $\begin{array}{l}\text { AVC, } \\
\text { TGA }\end{array}$ & $\begin{array}{l}\text { CoA-repair, banding } \\
\text { Senning repair }\end{array}$ & $\begin{array}{l}\text { Hepatic, coagulopathy } \\
\text { Stenosis PVA }\end{array}$ & $\begin{array}{l}\text { Hypervolaemia, oliguria } \\
\text { Low cardiac output, } \\
\text { Hypervolaemia, ARF }\end{array}$ \\
\hline $\begin{array}{l}4 \\
5 \\
6\end{array}$ & $\begin{array}{l}18 \text { months } \\
6 \text { weeks } \\
7 \text { days }\end{array}$ & $\begin{array}{l}\mathbf{M} \\
\mathbf{F} \\
\mathbf{M}\end{array}$ & $\begin{array}{l}9 \cdot 5 \\
1 \cdot 7 \\
3 \cdot 4\end{array}$ & $\begin{array}{l}\text { TF } \\
\text { DA, HMD } \\
\text { COA, VSD }\end{array}$ & $\begin{array}{l}\text { Total correction } \\
\text { Ligation of DA } \\
\text { CoA repair }\end{array}$ & $\begin{array}{l}\text { Residual VSD } \\
\text { Severe hypovolaemic shock } \\
\text { Renal hypoperfusion }\end{array}$ & $\begin{array}{l}\text { Low cardiac output, ARF } \\
\text { Hypervolaemia, ARF } \\
\text { Hypervolaemia, ARF }\end{array}$ \\
\hline
\end{tabular}

ARF, acute renal failure; AVC, atrioventricular canal; BTS, Blalock-Taussig shunt; CAVH, continuous arteriovenous haemofiltration, CoA, coarctation of aorta; HMD, hyaline membrane disease; IVS, intact ventricular septum; PA, pulmonary atresia; DA, ductus arteriosus; VSD, ventricular' septal defect; PVA, pulmonary venous atrium; TF, tetralogy of Fallot; TGA, transposition of the great arteries.

anticoagulation. In addition, epoprostenol (4-8 $\mathrm{ng} / \mathrm{kg} / \mathrm{min}$ ) was infused continuously into the arterial line of the extracorporal circuit in patients at high risk of bleeding. The ultrafiltrate was collected in a calibrated bag and measured every hour or half hour. A commercially available haemofiltration solution, a bicarbonate glucose solution, or a hyperalimentation fluid were used to replace the ultrafiltrate. A negative fluid balance of $1-3 \mathrm{ml} / \mathrm{kg} / \mathrm{h}$ was the initial aim of treatment. Arterial blood pressure and central venous pressure were monitored continuously during continuous arteriovenous haemofiltration. The mean (2 SD) values are given. Student's $t$ test for paired samples was to compare the mean values.

\section{Results}

Continuous arteriovenous haemofiltration for fluid removal lasted $57.5(31 \cdot 1)$ hours (range 29 to 140 hours). The mean ultrafiltration rate of $1 \cdot 1(0 \cdot 5)$ $\mathrm{ml} / \mathrm{min}$ produced a mean negative fluid balance of $1.4(0.6) \mathrm{ml} / \mathrm{kg} / \mathrm{h}$ and a mean calorie intake of 72.5 (6.9) $\mathrm{kcal} / \mathrm{kg} /$ day. Mean body weight decreased from $4.7(2.2 \mathrm{~kg}$ before haemofiltration to $4.2(2.3) \mathrm{kg}$ after haemofiltration. The mean total protein concentration increased from $4.5 \cdot(0.39)$ before haemofiltration to $5.4 \quad(0.45) \quad \mathrm{g} / \mathrm{dl}$ after haemofiltration. Table 2 shows the haemodynamic variables before and after haemofiltration. Figure 1 shows a 6 day course of continuous arteriovenous haemofiltration in a six week old infant (patient 3,

Table 2 Haemodynamic variables (mean (2.SD)) before and after continuous arteriovenous haemofiltration

\begin{tabular}{lccl}
\hline & Before CAVH & After CAVH & p value \\
\hline MAP (mm Hg) & $44.6(5.5)$ & $52.6(5.1)$ & $: 0.05$ \\
CVP (mm Hg) & $13.7(3.1)$ & $7.7(0.8)$ & 0.01 \\
HR (beats/min) & $149(13.3)$ & $-138(8.4)$ & NS \\
\hline
\end{tabular}

CAVH, continuous arteriovenous haemofiltration; CVP, central venous pressure; HR, heart rate; MAP, mean arterial pressure. table 1) with low cardiac output, very high blood volume, pulmonary oedema, and acute renal failure after having two open heart operations within 24 hours. At the start of haemofiltration a mean arterial pressure of only $38(4.9) \mathrm{mm} \mathrm{Hg}$ was achieved after high doses of catecholamine and a high preload. Slow and continuous removal of fluid increased the mean arterial pressure gradually to $58(6 \cdot 2) \mathrm{mm} \mathrm{Hg}$.

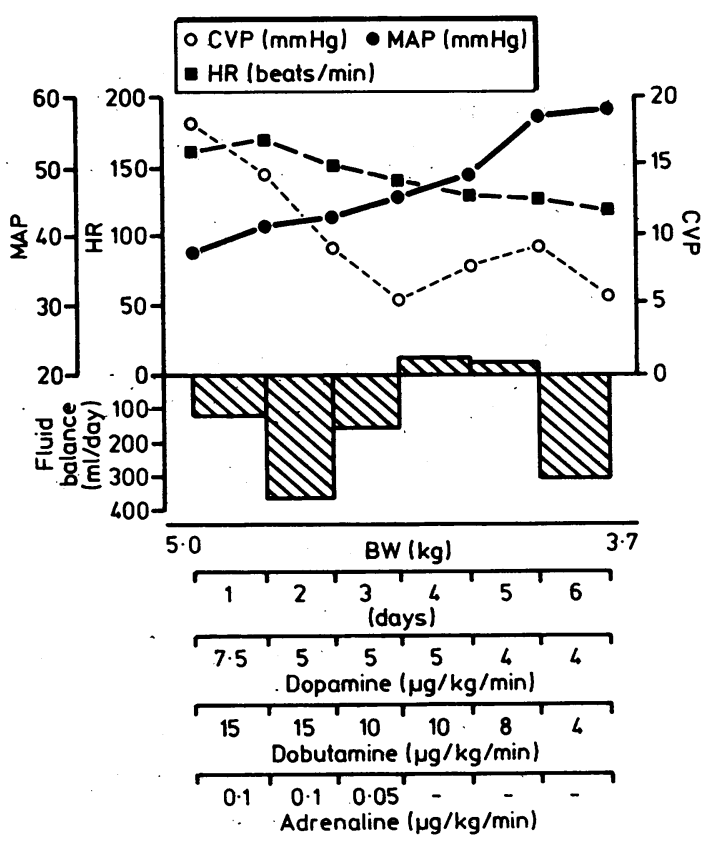

Fig 1 Haemodynamic variables during 6 days of continuous arteriovenous haemofiltration in a 6 week old infant with low cardiac output, considerably increased blood volume, pulmonary oedema, and anuria after cardiac surgery. Net fluid removal, $1.084 \mathrm{ml}$. Body weight decreased from 5.0 to $3.7 \mathrm{~kg}$. CVP, central venous pressure; $B W$, body weight; $H R$, heart rate; $M A P$, mean arterial pressure. 


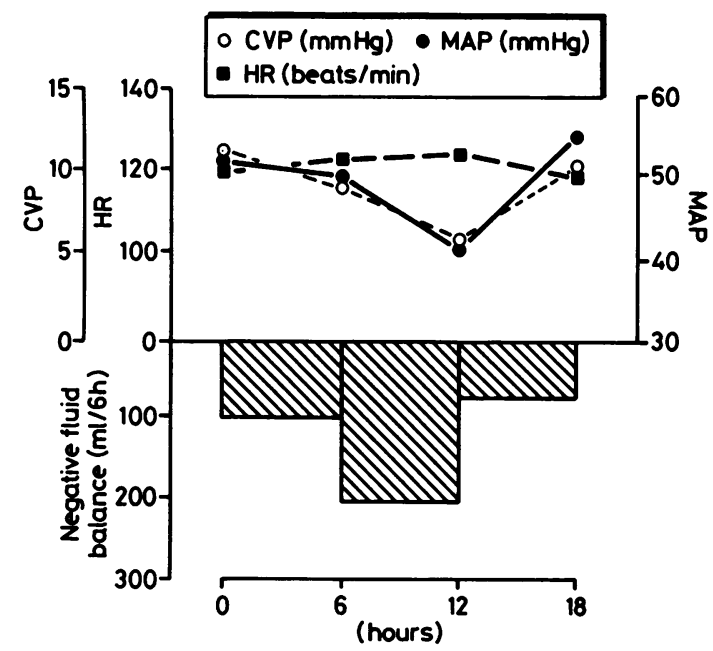

Fig 2 Haemodynamic variables and fluid balance during continuous arteriovenous haemofiltration in a 18 month old boy with low cardiac output and anuria after surgical repair of tetralogy of Fallot and residual ventricular septal defect. CVP, central venous pressure; HR, heart rate; $M A P$, mean arterial pressure.

This permitted a considerable reduction in the dose of catecholamines. After 6 days of continuous arteriovenous haemofiltration body weight had returned almost to normal.

Figure 2 shows the influence of preload on mean arterial pressure during continuous arteriovenous haemofiltration. During the first 12 hours a negative fluid balance of $207 \mathrm{ml}$ reduced central venous and mean arterial pressures significantly in a 18 month old boy who had low cardiac output and anuria but normal blood volume after surgical repair of tetralogy of Fallot and residual ventricular defect (patient 4 , table 1). An increase of his preload by colloid infusions increased the mean arterial pressure to baseline and catecholamines were no longer needed.

All but one patient could be weaned from mechanical ventilation and catecholamine treatment within $4 \cdot 2$ (3.1) days. Because of persisting anuria continuous arteriovenous haemofiltration had to be continued in three children after a normal blood volume had been achieved. No adverse affects on cardiovascular function were noted.

After 12 days of continuous arteriovenous haemofiltration one child had a femoral artery thrombosis that required operation. Four children were discharged from the hospital. Patient 2 died of hepatic failure three months after cardiac surgery and patient 6 had a sudden irreversible cardiac arrest on the seventh day of haemofiltration.

\section{Discussion}

Continuous arteriovenous haemofiltration removes fluids and solutes from the body by ultrafiltration. Since its first description by Kramer et al in $1977^{5}$ it has been successfully used in many critically ill adult patients with acute renal failure and haemodynamic instability. ${ }^{36}$ In 1985 Magilligan reported on the application of ultrafiltration before, during, and after cardiac surgery. ${ }^{7}$ Recently adult patients with considerably increased blood volumes caused by congestive heart failure refractory to standard treatment were successfully treated by ultrafiltration or haemofiltration..$^{8-10}$ There are no reports about the use of continuous arteriovenous haemofiltration in children with congestive heart failure after cardiac surgery.

In patients with acute renal failure and gross oedema high intravascular and low plasma oncotic pressures increase the fluid flux from the intravascular to the interstitial space. Removal of fluid will be effective only if there is adequate replacement of interstitial fluid to prevent hypotension. This is why intermittent haemodialysis is not well tolerated by critically ill patients with haemodynamic instability. ${ }^{11}$ Slow and continuous removal of fluid during continuous arteriovenous haemofiltration, however, does result in adequate vascular refilling. Furthermore, the slight increase in plasma oncotic pressure during ultrafiltration facilitates the redistribution of fluid from the interstitial to the intravascular space. This fluid shift can be enhanced by intermittent intravenous colloid infusions. In our patient no hypotensive reactions occurred during continuous arteriovenous haemofiltration when the rate of removal of fluid was between $1-3 \mathrm{ml} / \mathrm{kg} / \mathrm{h}$.

Recently Lauer et al reported an increase in cardiac index during continuous arteriovenous haemofiltration in fluid overloaded patients with congestive heart failure. ${ }^{12}$ Magilligan noticed an increase of radionuclide ejection fraction from $37 \%$ preoperatively to $60 \%$ after ultrafiltration in a patient with diuretic resistant congestive heart failure. ${ }^{7}$ Cardiac output was not measured in our critically ill children. The significant increase of mean arterial pressure during fluid removal by continuous arteriovenous haemofiltration in our patients with fluid overload, however, might indicate increased cardiac output. Like Nordbeck et al we noticed that continuous arteriovenous haemofiltration allowed us to set the central venous pressure to optimise cardiac output. ${ }^{2}$ At this point a reduction in the dose of catecholamine can be tried.

Continuous arteriovenous haemofiltration is a safe and effective treatment that improves cardiovascular function by preload reduction in hypervolaemic chil- 
dren with congestive heart failure. It can be installed quickly in every paediatric intensive care unit and is well tolerated even by small children with severe cardiovascular instability. It permits adequate nutritional support during fluid removal. Adverse affects such as hypotension, bleeding, or arterial thrombosis are rare.

\section{References}

1 Levin DL, Perkin RM. Postoperative care of the paediatric patient with congenital heart disease. In: Shoemaker WC, Thompson WL, Holbrook PR, eds. Textbook of critical care. Philadelphia: WB Saunders, 1984:395-403.

2 Nordbeck $H$, Blanke $H$, Kaiser $H$, Kreuzer $H$. Importance of continuous and slow fluid withdrawal in patients with impending cardiogenic shock. In: Kramer P, ed. Arteriovenous haemofiltration. Berlin, Heidelberg: Springer, 1985:167-73.

3 Kramer P, Wigger W, Rieger J, Matthaei D, Scheler F. Arteriovenous haemofiltration: a new and simple method for treatment of over-hydrated patients resistant to diuretics. Klin Wochenschr 1977;55: 1121-22.

4 Zobel G, Ring E, Trop M, Grubbauer HM. Suctionsupported continuous arteriovenous haemofiltration in children. Blood Purification 1987 (in press).
5 Zobel G, Trop M, Ring E, Grubbauer HM. Nine months experience with $\mathrm{CAVH}$ in a paediatric intensive care unit. In: La Greca G, Fabris A, Ronco C, eds. Proceedings of the international symposium on continuous arteriovenous haemofiltration. Milano: Wichtig Editore, 1986: 155-61.

6 Lauer A, Saccaggi A, Ronco C, Belledonne M, Glabman S, Bosch JP. Continuous arteriovenous haemofiltration in the critically ill patient. Ann Intern Med 1984;99:455-60.

7 Magilligan DJ. Indications for ultrafiltration in the cardiac surgical patient. J Thorac Cardiovasc Surg 1985;89:183-9.

8 Donato L, Biagini A, Contini C, et al. Treatment of end-stage congestive heart failure by extracorporal ultrafiltration. Am J Cardiol 1987;59:379-80.

9 Morgan SH, Mansell MA, Thompson FD. Fluid removal by haemofiltration in diuretic resistant cardiac failure. $\mathrm{Br}$ Heart $J$ 1985;54:218-9.

10 Simpson IA, Rae AP, Simpson K, et al. Ultrafiltration in the management of refractory congestive heart failure. Br Heart J 1986;55:344-7.

11 Thompson FD, Mansell MA. Renal failure. Clinics in Anaesthesiology 1985;4:955-71.

12 Lauer A, Alvis RC, Avram MM. Haemodynamic consequences of continuous arteriovenous haemofiltration in intractable fluid overload. In: La Greca G, Fabris A, Ronco C, eds. Proceedings of the international symposium on continuous arteriovenous haemofiltration. Milano: Wichtig Editore, 1986: 227-31. 